ACCEPTED MANUSCRIPT

\title{
Mechanical evaluation of polylactic acid (PLA) based composites reinforced with different calcium phosphates
}

To cite this article before publication: Claudio Javier Perez et al 2018 Mater. Res. Express in press https://doi.org/10.1088/2053-1591/aadb5b

\section{Manuscript version: Accepted Manuscript}

Accepted Manuscript is "the version of the article accepted for publication including all changes made as a result of the peer review process, and which may also include the addition to the article by IOP Publishing of a header, an article ID, a cover sheet and/or an 'Accepted

Manuscript' watermark, but excluding any other editing, typesetting or other changes made by IOP Publishing and/or its licensors"

This Accepted Manuscript is @ 2018 IOP Publishing Ltd.

During the embargo period (the 12 month period from the publication of the Version of Record of this article), the Accepted Manuscript is fully protected by copyright and cannot be reused or reposted elsewhere.

As the Version of Record of this article is going to be / has been published on a subscription basis, this Accepted Manuscript is available for reuse under a CC BY-NC-ND 3.0 licence after the 12 month embargo period.

After the embargo period, everyone is permitted to use copy and redistribute this article for non-commercial purposes only, provided that they adhere to all the terms of the licence https://creativecommons.org/licences/by-nc-nd/3.0

Although reasonable endeavours have been taken to obtain all necessary permissions from third parties to include their copyrighted content within this article, their full citation and copyright line may not be present in this Accepted Manuscript version. Before using any content from this article, please refer to the Version of Record on IOPscience once published for full citation and copyright details, as permissions will likely be required. All third party content is fully copyright protected, unless specifically stated otherwise in the figure caption in the Version of Record.

View the article online for updates and enhancements. 


\section{Mechanical evaluation of polylactic acid (PLA) based composites}

\section{reinforced with different calcium phosphates}

Claudio Javier Pérez ${ }^{1}$, Patricia Eisenberg ${ }^{2}$, Celina Bernal ${ }^{3,4}$, Ezequiel Pérez $^{2,3 *}$

${ }^{1}$ Polymer Science and Engineering Group, Materials Science and Technology Research Institute (INTEMA) - National University of Mar del Plata (UNMdP), Av. Juan B. Justo 4302, (7600) Mar del Plata, Argentina.

${ }^{2}$ Plastics Research and Development Center, National Institute of Industrial Technology (INTI-Plásticos), Av. Gral. Paz 5445 (B1650KNA), General San Martín, Buenos Aires, Argentina.

${ }^{3}$ National Scientific and Technical Research Council (CONICET), Av. Rivadavia 1917 (C1033AAJ), Buenos Aires, Argentina. E-mail: eperez@inti.gob.ar, Phone: +54 (11) 48995400.

${ }^{4}$ Institute of Technology in Polymers and Nanotechnology, ITPN (UBA-CONICET), Engineering Faculty, University of Buenos Aires, Av. Las Heras 2214 (C1127AAR), Buenos Aires, Argentina. 


\begin{abstract}
In the present work, the mechanical performance of polylactic acid (PLA) based composites reinforced with hydroxyapatite (HA) or $\beta$-tricalcium phosphate $(\beta$-TCP) was investigated. The polymer was melt compounded with 1 and $2.5 \mathrm{wt} . \%$ of particles by using an intensive mixer or a twin screw extruder. Morphological, thermal and rheological studies were performed to analyze the composites internal structure and filler-matrix interaction. The mechanical behavior was investigated through uniaxial tensile and quasi-static fracture tests. The different characterization techniques evidenced a better filler dispersion for composites obtained by extrusion independently of the filler used. A relatively weak filler-matrix interaction was revealed from morphological observations and rheological measurements. In addition, thermal analysis evidenced similar crystalline structure for all of the investigated materials. In general, uniaxial tensile parameters displayed almost constant values independently of the filler content or compounding method. Particularly, extruded composites with 2.5 wt.\% filler exhibited slightly increased ductility respect to neat PLA which was related to improved filler dispersion. The PLA matrix displayed load-displacement curves with ductile instability in quasi-static fracture tests. On the other hand, the composites with 2.5 wt.\% filler exhibited an increased stable crack growth followed by ductile instability. The fracture process was quantitatively described by means of critical stress intensity factor $\left(K_{I Q}\right)$ and strain energy release rate at propagation $\left(G_{C P}\right)$ parameters. The extruded composites with 2.5 wt.\% filler displayed improved propagation fracture toughness. Based on fractured surfaces analysis this enhanced behavior, not largely reported for untreated rigid fillers, was attributed to the effective activation of the toughening mechanisms of particle debonding and subsequent plastic void growth.

\section{Keywords}

Polylactic acid (PLA), Calcium phosphates, Mechanical properties, Fracture toughness 


\section{Introduction}

Biodegradable polymers such as polylactic acid (PLA), polyglycolic acid (PGA), poly- $\varepsilon$-caprolactone (PCL), polyhydroxylbutyrate (PHB), starch, chitosan, their blends and composites are extensively used in a wide range of applications, including agriculture, packaging, or biomedical products [1-5]. These polymers can be reinforced with fillers such as: hydroxyapatite (HA), $\beta$-tricalcium phosphate $(\beta-\mathrm{TCP})$, amorphous calcium phosphate $(\mathrm{ACP})$, biphasic calcium phosphate $(\mathrm{BCP})$, clay, silica and cellulose among others, to obtain composite materials with enhanced performance [2-9]. Particularly, the mechanical behavior of polymer based composites has been related to a wide range of factors and characteristics [8-9]. The effect of the filler (reinforcement type, geometry, size distribution, content, surface condition) and processing (injection, extrusion, compression molding) should be considered as key factors [1, 6, 10-15].

Many works have been reported in the literature about PLA-calcium phosphates composites, mainly focused on the chemical or thermal properties, filler surface modifications, morphology, degradation, bioactivity, among others. However, mechanical performance has been generally limited to some specific tests and parameters disregarding an exhaustive analysis of fracture behavior or failure mechanisms [2-3, 8, 12, 16-19]. In addition, different filler type, size and content, filler-matrix combination and/or testing geometry were used. For this reason, comparison among already published results can be really complex or even impossible. Shikinami et al. obtained PLA-HA composites (particle size distribution: $0.3-0.5 \mu \mathrm{m}$, filler content: $20-50 \%$ ) with enhanced bending, shear and impact performance [20]. For PLA reinforced with unmodified HA particles (particle mean length: $2.1 \mu \mathrm{m}$, filler content: $25-50 \%$ ) an embrittlement effect in compression behavior has been reported by Gay et al. [8]. Hong et al. observed decreased tensile and bending strength values with the incorporation of unmodified HA (particle mean length: $100 \mathrm{~nm}$, filler content: 
2.5-20\%) into PLA [14]. Niemelä [21] reported lower tensile performance with $\beta$-TCP (particle size distribution: 50-125 $\mu \mathrm{m}$, filler content: $20 \%$ ) while Jin et al., for the same filler, published improved compressive behavior (particle size distribution: not reported, filler content: 10-30\%) [22]. Due to the fact that processing can influence filler dispersion or orientation into the polymer matrix, Mathieu et al. compared three compounding methods for PLA based composites reinforced with HA (specific surface area: $50 \mathrm{~m}^{2} / \mathrm{g}$, filler content: 5$15 \%$ ) or $\beta$-TCP (specific surface area: $1.5 \mathrm{~m}^{2} / \mathrm{g}$, filler content: $5-15 \%$ ). They observed improved filler dispersion by melt extrusion, but there was no enhancement of the composites tensile properties [23]. Rakovsky et al. reported a higher compressive strength for PLA- $\beta$ TCP composites (size distribution: 100-300 nm, filler content: $40 \%$ ) [24]. In general, most of the published data about PLA-calcium phosphates composites disregarded fractographic characteristics of tested samples and the discussion about which fracture mechanisms were involved during the failure process.

It should be highlighted, the mechanical properties depend on the specific fillermatrix combination used making prediction complicated. In addition, unfortunately, many studies did not exhaustively report composite materials characteristics, processing and experimental behavior observed $[5,8,12,14,18,20,25-27]$. For these reasons, the reinforcement effect of phosphates on PLA matrices still remains under discussion, meaning that additional and more detailed mechanical performance analysis are required to clearly identify the most relevant involved factors.

In the present work, the mechanical behavior of PLA based composites reinforced with HA or $\beta$-TCP particles was evaluated. The effect of these two different calcium phosphates, their size distributions, particle content and processing on the tensile and fracture behavior was investigated. Furthermore, the fracture process was quantified by fracture toughness parameters and qualitatively described by fractographic characteristics. 
Particularly, this work focused on the relationship, not yet clearly established for PLAcalcium phosphates composites, between toughening mechanisms and the most relevant composite characteristics required for their effective activation. 


\section{Materials and methods}

\subsection{Composites preparation}

A commercial polylactic acid (PLA) (Ingeo 7001D, NatureWorks LLC) was used as the matrix (melt flow index: $6 \mathrm{~g} / 10 \mathrm{~min}$ ). Hydroxyapatite (HA) (Institute of Biomedical Engineering, University of Buenos Aires) [28] and $\beta$-tricalcium phosphate ( $\beta$-TCP) (Sigma Aldrich) were employed as the fillers. Different composites were prepared with: 1 and 2.5 wt. $\%$ of particle (referred as: PLA-HA, PLA- $\beta$-TCP in the following text). The components were compounded by using an intensive mixer (Brabender Plasticorder, at $190^{\circ} \mathrm{C}$ and $50 \mathrm{rpm}$ for $10 \mathrm{~min}$ ) or a twin screw extruder (Thermo Scientific Process 11, temperature profile: $160^{\circ} \mathrm{C}, 170^{\circ} \mathrm{C}, 180^{\circ} \mathrm{C}, 190^{\circ} \mathrm{C}, 190^{\circ} \mathrm{C}, 190^{\circ} \mathrm{C}, 220^{\circ} \mathrm{C}$ at $50 \mathrm{rpm}$ ). Composites films (nominal thickness $B=0.25 \mathrm{~mm}$ ) were obtained by compression molding in a hydraulic press $(\mathrm{T}=190$ ${ }^{\circ} \mathrm{C}, \mathrm{P}=50 \mathrm{MPa}, \mathrm{t}=10 \mathrm{~min}$ ) followed by rapid cooling within the press plates under constant pressure by circulating water.

\subsection{Particles characterization}

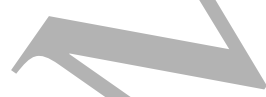

Particle size distributions were obtained with a Master Sizer Micro (Malvern Instrument). The analyzed fillers were ultrasonically dispersed in deionized water for $10 \mathrm{~min}$ before measurements. The Z potential of HA and $\beta$-TCP was measured (Nicomp ZLS Z3000) at $25^{\circ} \mathrm{C}$ with $\mathrm{DI} \mathrm{H}_{2} \mathrm{O}$.

\subsection{Morphology and fracture surface analysis}

Dispersion of the fillers into the PLA matrix was examined by Scanning Electron Microscopy (SEM) (FEI QUANTA 250). In addition, fracture surface morphology of tested samples wàs also observed by SEM. 


\subsection{Thermal characterization}

Thermal analysis was performed under nitrogen atmosphere at a heating rate of $10^{\circ} \mathrm{C} / \mathrm{min}$ in the range of 25 to $230^{\circ} \mathrm{C}$ (Perkin Elmer Pyris 1 Differential Scanning Calorimeter (DSC)). Crystallinity $\left(X_{c}\right)$ of the different materials was determined from the DSC curves with the following expression:

$$
X c(\%)=\frac{\left(\Delta H_{m}-\Delta H_{c}\right)}{\Delta H^{0} \times W_{p}} \times 100
$$

where: $\Delta H_{m}$ is the melting enthalpy, $\Delta H_{c}$ is the cold crystallization enthalpy, $\Delta H^{0}(93 \mathrm{~J} / \mathrm{g})$ is the $100 \%$ crystalline PLA melting enthalpy and $W_{p}$ is the polymer weight fraction [19].

\subsection{Rheological characterization}

The complex viscosity $\left(\eta^{*}\right)$, storage modulus $\left(G^{\prime}\right)$ and loss modulus $\left(G^{\prime \prime}\right)$ were obtained in small-amplitude oscillatory shear flow experiments using a rotational rheometer (Anton Paar Rheometer MCR-301) provided with a CTD 600 thermo chamber. The tests were carried out at $165^{\circ} \mathrm{C}$ using parallel plates of $25 \mathrm{~mm}$ diameter with a strain of $\gamma=1.0 \%$, dynamic strain sweep was initially conducted to determine the linear viscoelastic region, within a frequency range of $0.1-500 \mathrm{~s}^{-1}$.

\subsection{Mechanical characterization}

Uniaxial tensile tests were performed in a INSTRON 1125 dynamometer at a crosshead speed of $5 \mathrm{~mm} / \mathrm{min}$ by following ASTM D882-02 standard recommendations. Characteristic stress-strain curves and parameters were obtained from these tests. Quasi-static fracture tests were also carried out at $1 \mathrm{~mm} / \mathrm{min}$ on deeply double edge-notched tensile (DDENT) specimens (length $(L)=30 \mathrm{~mm}$, depth $(W)=20 \mathrm{~mm}$, notch $(a)=5 \mathrm{~mm}$, thickness $(B)=0.25 \mathrm{~mm})$.

The crack initiation was evaluated by the critical stress intensity factor $\left(K_{I Q}\right)$ as [29]: 


$$
K_{I Q}=\frac{F_{q}}{B \sqrt{\frac{W}{2}}} f\left(\frac{a}{W}\right)
$$

where: $F_{q}$ is the load at crack initiation (obtained by a secant line with a $95 \%$ of the initial elastic loading slope) and $f\left(\frac{a}{W}\right)$ is the geometrical factor defined by [29-30]:

$$
f\left(\frac{a}{W}\right)=\frac{\sqrt{\frac{\pi a}{2 W}}}{\sqrt{1-\frac{a}{W}}}\left[1.122-0.561\left(\frac{a}{W}\right)-0.205\left(\frac{a}{W}\right)^{2}+0.471\left(\frac{a}{W}\right)^{3} 0.149\left(\frac{a}{W}\right)^{4}\right]
$$

Propagation fracture toughness was characterized by the strain energy release rate $\left(G_{c p}\right)$ as follows [20]:

$$
G_{c p}=\frac{U_{t}}{B(W-a)}
$$

where: $U_{t}$ is the overall fracture energy.

All mechanical tests were performed at room temperature. A minimum of five samples were tested for each material and the average values with their deviations were reported. 


\section{Results and discussion}

\subsection{Calcium phosphate filler analysis}

Particle size distributions for both filler used are presented in figure 1. For HA, a bimodal broad distribution $(0.4-140 \mu \mathrm{m})$ was obtained with most frequent values of $3.40 \mu \mathrm{m}$ and $41.40 \mu \mathrm{m}$. For $\beta$-TCPa unimodal narrower distribution was observed $(0.4-60 \mu \mathrm{m})$ with a most frequent value of $6.10 \mu \mathrm{m}$. On the other hand, the zeta potential values obtained were: $4 \mathrm{mV}$ for $\mathrm{HA}$ and $-32 \mathrm{mV}$ for $\beta$-TCP particles. It can be found in the literature a higher agglomeration tendency for fillers with reduced sizes and/or low surface charge [11, 31-32]. Based on the obtained results, the smaller HA particles could be largely agglomerated due to the zeta potential value. While, for $\beta$-TCP counteracting effects can be considered. On one hand a higher agglomeration tendency, related to the increased frequency of small filler sizes, but on the other hand the larger repulsive electrostatics forces.

\subsection{Morphological analysis}

Figure 2 shows typical SEM micrographs for PLA-HA and PLA- $\beta$-TCP composites samples obtained with the different compounding methods. It can be observed that, both fillers were locally agglomerated (indicated by arrows) but they were also clean of the matrix material suggesting a relatively low interfacial adhesion between both phases. Otherwise, for higher interactions, the filler should be coated by the matrix and hardly distinguishable [33]. Similar morphologies have been reported for untreated calcium phosphates composites [14, $23,34-35]$. In addition, for composites obtained with the extruder reduced agglomerates frequency was obseryed (fígure 2.b) suggesting a more efficient melt compounding in this case. 


\subsection{Thermal analysis}

The second heating DSC scans for the materials processed with the twin screw extruder are shown in figure 3. A cold crystallization effect was detected as well as the presence of a double melting peak related to a polymorphism and melt recrystallization of the unstable crystals formed during the cold crystallization process [36]. The filler/effectiveness on the crystallization and thermal behavior strongly depends on particle dispersion, size, shape, surface characteristics and content, among others [37-39]. Particularly, it has been reported that the incorporation of HA can influence the PLA matrix in different ways [39-41]. Liu et al. explained the retardant nucleating effect due to the chemistry of HA [40]. On the other hand, Zhou et al. discussed the nucleating efficiency of spherical HA nanoparticles [41]. In addition, Persson et al. observed a dropped of the crystallization peak with HA content and increased crystallinity at filler loadings larger than $15 \mathrm{wt} \%$. They discussed the ability of HA to form PLA crystals at lower temperatures or to act as a nucleating agent [39]. Frone et al. reported the thermal performance of PLA-cellulose nanofibers composites [36]. They observed a shift of $\mathrm{T}_{\mathrm{cc}}$ to lower values with untreated cellulose while for silane treated cellulose cold crystallization temperature increased. The authors explained this behavior in terms of an improvement of the filler-matrix adhesion that hindered the polymer chain mobility. Shi et al. analyzed the crystallization behavior of PLA reinforced with precipitated calcium carbonate (PCC) and halloysite natural nanotubes (HNT) [42]. They observed lower $\mathrm{T}_{\mathrm{cc}}$ values with PCC content. The enhanced crystallization behavior was explained by the simultaneous increase of contact surface area and nucleating sites.

In general, for the investigated materials no clear trends of thermal properties (table 1) were observed irrespectively of the composition or processing method. The quite constant $T_{g}$ value can be explained by the low filler loading considered [36]. In this situation, only a marginal fraction of PLA chains could be restricted by the particles and DSC scanning was 
not sufficiently sensitive to properly detect this effect [36]. The lack of variation of $\mathrm{T}_{\mathrm{m}}$ also confirmed the not restricted polymer chain mobility [42]. In addition, the constant melting temperature suggested similar crystalline structure for all of the investigated materials [36]. However, for extruded composites, both fillers promoted the PLA crystallization at lower temperatures as detected by the shift of the $\mathrm{T}_{\mathrm{cc}}$ values, similarly to the reported results for other reinforcements above mentioned.

\subsection{Rheological analysis}

The rheological behavior of the PLA based composites obtained with the twin screw extruder is displayed in figure 4. The $\eta^{*}$ and $\mathrm{G}^{\prime}$ parameters showed increased values, compared to the neat PLA, with filler content related to a hydrodynamic effect due to the presence of the particles into the polymer [3]. Particularly, the PLA-2.5 wt.\% $\beta$-TCP composite exhibited the largest increment on the complex viscosity. In addition, composite materials can reach a solid-like behavior due to filler interactions and easily achieved with reduced filler sizes [3, 43-44]. The $\mathrm{G}^{\prime}$ curves of composites displayed a rheological behavior close to a frequency-independent plateau suggesting that a percolated network was not fully developed. Similar rheological behaviors were obtained for the composites compounded with the intensive mixer (results not shown here).

The composites interaction and structure were also analyzed by the Han and ColeCole diagrams. Taking into account the Han plot, slope variations for composites compared to the neat matrix are related to the filler-matrix interaction and to a more complex internal structure. In addition, a shift to higher frequencies of the inflection point suggests larger energy required to modify the internal structure due to higher contact area or stronger interactions [45-46]. Li et al. investigated the rheological performance of PLA reinforced with silica [46]. They observed notable variations of the slope and the inflection point beyond 
percolation threshold, meaning that strong internal interactions were achieved. Figure 4.c shows for the composites a reduced slope, independently of the filler type or content. The lack of variation of the inflection point indicates an almost constant energy consumed to modify the internal structure probably due to the low filler content, to a weak filler-matrix interaction or to the superposition of both effects.

Taking into account the Cole-Cole diagram, a perfect arc means a single relaxation time distribution. The presence of internal structures such as: agglomeration, internal network, house-of-cards or skeleton, among others are detected by the presence of a tail or a second arc. In addition, for composite material diagrams two parts can be analyzed: a half-arc at low viscosities related to the local dynamic of polymer and a rigid tail at higher viscosities in accordance with long-term relaxation times of restrained polymer chains [47-48]. PLA- $\beta$ TCP composites (figure 4.d) exhibited a tail independently of the filler content and compounding method. In addition, the rigid tail of extruded composites displayed a higher slope compared to the internal mixer ones. This behavior observed for extruded composites, suggests a larger influence of the restrained polymer chains on the whole relaxation spectrum that can be achieved by a more ordered internal network [41, 45-46]. Similar effect of the compounding method was found for the PLA-HA composites (results not shown here).

\subsection{Mechanical performance analysis}

\section{Uniaxial tensile behavior}

Figures 5 and 6 display stress-strain curves and tensile parameters values for the different materials investigated. In general, neat PLA and the composites exhibited similar tensile behavior characterized by the presence of a yield point followed by strain softening before final fracture. Elastic modulus, tensile strength and strain at break values did not show significant variations among the different composites. Particularly, the slight variations of 
composite tensile strength values confirmed the relatively weak filler-matrix interaction previously observed by SEM [10-11]. The effect of filler size, content and filler-matrix adhesion on the strength of particulate polymer composites has been reviewed by Fu et al. [10]. Briefly, they analyzed the relevance of interfacial strength related to the load transfer capability from the polymer matrix to the rigid fillers. For composites with well dispersed particles and strong bonding, filler content leads to increased strength particularly for nanocomposites due to the larger surface contact area. In addition, tensile strength can be also affected by the polymer crystallinity $[10,40]$. The thermal analysis described before suggests quite similar crystalline structure for all of the investigated materials. For this reason, it should not be considered as a key factor to explain their mechanical performance. Composites with 2.5 wt.\% filler processed with the intensive mixer exhibited lower ductility respect to neat PLA probably due to the presence of large agglomerates. On the contrary, the same composite material obtained by extrusion showed slightly enhanced post-yield behavior that has been related in the literature to improved filler dispersion [10].

SEM fractographs of samples broken in tensile tests (figure 7) exhibited, in general, smooth fracture surfaces related to the absence of significant dissipation mechanisms [49-50]. For the composites processed with the intensive mixer (figure 7.a.2 and 7.a.3), larger agglomerates (indicated by arrows) able to promote easy crack growth were observed. In addition, for all of the composites investigated fracture surfaces did not reveal generalized particle debonding suggesting this toughening mechanism was not properly activated under uniaxial tensile loading.

\section{Quasi-static fracture behavior}

For neat PLA, load-displacement curves obtained in quasi-static fracture tests (figure 8) showed fracture behavior with ductile instability characterized by an almost instantaneous 
drop of load from the maximum to zeroand related to a low propagation energy [51]. In accordance with this observation, lateral views of PLA samples did not display any signs of permanent damage such as stress whitening. On the other hand, composites exhibited a slight increase of stable crack growth displaying nonlinear load-displacement behavior, followed by ductile instability after the maximum load. In addition, tested samples of composites displayed different levels of stress whitening which can be extensively observed for extruded PLA-2.5 wt $\% \beta$-TCP. It should be highlighted that, the $2.5 \mathrm{wt} \%$ HA composite processed with the intensive mixer exhibited similar fracture behavior to neat PLA.

Figure 9 displays initiation and propagation fracture toughness values for the different materials investigated. Crack initiation toughness values (figure 9.a.1 and 9.a.2) for PLA-HA remained almost constant independently of the filler content or processing method used. On the other hand, for extruded PLA- $\beta$-TCP composites the $K_{I Q}$ values were improved respect to neat PLA. In general, propagation fracture toughness (figure 9.b.1 and 9.b.2) exhibited increased values for both fillers irrespectively of the processing method (except for the PLA2.5 wt.\% HA composite processed with the intensive mixer). It can be highlighted that, the lower scatter of values for extruded composites also suggests improved filler dispersion.

Pukánszky et al. proposed a theoretical model for strain energy release rate $\left(\ln \left(G_{C r e l}\right)=\ln \frac{G_{C}}{G_{C m}} \frac{\frac{E}{E_{m}}(1+2.5 \varphi)}{(1-\varphi)}=B \varphi\right)$ predictions as a function of the filler content. This model can be applied (figure 10) to analyze the filler-matrix interaction and particle dispersion [52-54]. The decreasing trend of $\ln \left(\mathrm{G}_{\text {crel }}\right)$ values with filler content suggests filler agglomerations, as can be observed for PLA-HA processed with the intensive mixer (figure 10.a). On the other hand, the increasing trend values for the extruded composites can be related to an improvement of filler dispersion. In addition, the linear regression slopes indicate similar filler-matrix interactions for both systems. 
In a similar way as previously described for the uniaxial tensile behavior, for neat PLA smooth surfaces (figure 11) with localized ductile tearing were observed. In addition, composite materials displayed rougher surfaces with more frequent ductile tearing. It can be highlighted for the PLA-2.5 wt.\% composites (figure 11.b.3), the evidence of particle debonding followed by plastic void growth and subsequent matrix ductile tearing. The air gap placed around the filler (indicated by arrows) had not been previously detected in the morphological analysis, meaning that particles were initially bonded to the polymer matrix. The enhancement of fracture toughness parameters and fracture surface morphology also suggests increased ductility.

Briefly, composites propagation fracture toughness was enhanced respect to neat PLA (except for the PLA-2.5wt.\% HA composite processed with the intensive mixer). Particularly, extruded composites displayed improved filler dispersion, meaning that the mechanical performance observed can be related to the concomitant effect of a good filler dispersion in the PLA matrix and a relatively low filler-matrix interaction that promote particle debonding and subsequent plastic void growth [10-11, 51, 55-57]. More specifically, the favorable effect of weak interactions should be discussed. It is commonly assumed for polymer based composites the need to improve filler-matrix interaction to successfully obtain enhanced performance. This point of yiew is really accurate for a wide range of physical and/or mechanical properties but not for all of them. Stronger interactions can promote higher tensile strength, barrier properties, and thermal stability, among others $[4,14,46]$. On the contrary, composite materials toughness represents an energetic phenomena meaning that energy dissipation mechanisms, elastic-plastic deformation process and energy release rates should be taken into account and not only the load bearing capability of the investigated system [55$56,58]$. Thio et al. reported improved toughness for $\mathrm{PP} / \mathrm{CaCO}_{3}$ composites and concluded that weaker adhesion promotes earlier debonding leading to extensive matrix plastic 
deformation [58]. In a similar way, Fu et al. argued that low interfacial adhesion is favorable for brittle matrix if micro-cavitation and/or micro-debonding is properly activated [10]. Finally, the results obtained in this work suggest that, toughening of PLA-calcium phosphates composites can be achieved even without filler modification or the incorporation of any compatibilizer provided filler particles are adequately dispersed. The results of this investigation seem to be very promising for biomedical applications, where biodegradable materials are extensively investigated and improved performances are still required [4-5]. 


\section{Conclusions}

PLA based composites reinforced with calcium phosphates were melt compounded by intensive mixing and twin screw extrusion. Morphological analysis displayed improved filler dispersion with only marginal agglomerates for the extruded composites. In addition, SEM observations suggested a relatively poor filler-matrix interaction for both particles. Thermal analysis indicated the fillers capability to induce the PLA crystallization at lower temperatures but an almost constant crystalline structure was also detected for all composites. This result suggests that reinforcement effect should be more dominant instead of nucleating one on the mechanical performance of the investigated composite materials. On the other hand, the rheological behavior indicated a more ordered internal structure for extruded composites. Taking into account the mechanical performance, extruded composites with 2.5 wt.\% filler exhibited slightly increased strain at break values in uniaxial tensile tests. In a similar way, propagation fracture toughness values $\left(G_{c p}\right)$ were higher for extruded composites compared to neat PLA. Fractured surfaces suggested that particle debonding and subsequent plastic void growth were the main toughening mechanisms.

It can be remarked that, the internal structure and filler-matrix interaction were analyzed by different experimental methodologies due to their close relationship to the mechanical performance of composite materials. In this way, the results of this investigation indicated that toughness of PLA-calcium phosphates composites can be improved with untreated particles. However, a properly filler dispersion superimposed with a relatively low interaction are required for the effective activation of the energy absorption mechanisms. Furthermore, dispersion was more relevant on the tensile and fracture behavior, rather than the filler type or the particle size distribution. In addition, the trends observed for propagation fracture toughness revealed that maximum values have not still been reached, and further 
improvements could be probably achieved with larger filler contents. Hence, further work is in progress to confirm these expectations. 


\section{Acknowledgments}

The authors are grateful for the financial support of the National Research Council of Argentina (CONICET), the FONCyT (PICT 2014-1955, PICT 2014-2654), the University of Buenos Aires (UBACyT 20020130200282BA) and the National Institute of Industrial Technology (INTI). 


\section{References}

1. Rothen-Weinhold A, Besseghir K, Vuaridel E, Sublet E, Oudry N, Kubel F and Gurny R 1999 Euro. J. Pharma. Biopharma.48 113-21

2. Wu D, Zhang Y, Zhang M and Zhou W 2008 Euro. Pol. J. 44 2171-83

3. Hao X, Kaschta J and Schubert DW 2016 Comp.Part B 89 44-53.

4. Armentano I, Dottori M, Fortunati E, Mattioli S and Kenny JM 2010 Pol. Deg. Stab.95 $2126-46$

5. Narayanan G, Vernekar VN, Kuyinua EL and Laurencin CT 2016 Adv. Drug. Del. Rev. $107247-76$

6. Kasuga T, Ota Y, Nogami M and Abe Y 2001 Biomat. 22 19-23

7. Surynegara L, Nakagaito AN and Yano H 2009Comp. Sci. Tech. 69 1187-92

8. Gay S, Arostegui S and Lemaitre J 2009 Mat. Sci. and Eng. C 29 172-7

9. Jin HH, Min SH, Song YK, Park HC and Yoon SY 2010 Pol. Deg. and Stab. 95 1856-61

10. Fu SY, Feng XQ, Lauke B and Mai YW 2008 Compos. Part B 39 933-61

11. Móczó J and Pukánszky B 2008 J. Ind. Eng. Chem. 14 535-63

12. Li J, Lu XL and Zheng YF2008 App. Surf. Sci. 255 494-97

13. Corcione CE, Gervaso F, Scalera F, Montagna F, Maiullaro T, Sannino A and Maffezzoli A 2017J. Pol. Eng. 37(8) 741-746

14. Hong Z, Zhang P, He C, Qiu X, Liu A, Chen L, Chen X and Jing X 2005 Biomat. 26 6296-304

15. Mano JF, Sousa RA, Boesel LF, Neves NM and Reis RL 2004 Comp. Sci. and Tech. 64 $789-817$

16. Zhou H, Lawrence JG and Bhaduri SB 2012 Acta. Biomat. 8 1999-2016

17. Wang M 2003 Biomat. 24 2133-51

18. Lin PL, Fang HW, Tseng T and Lee WH 2007 Mat. Lett. 61 3009-13 
19. Wootthikanokkhan J, Cheachun T, Sombatsompop N, Thumsorn S, Kaabbuathong N, Wongta N, Wong-On J, Ayutthaya SIN and Kositchaiyong A 2013 J. Appl. Pol. Sci. 129(1) 215-23

20. Shikinami Y and Okuno M 1999 Biomat. 20 859-77

21. Niemelä T 2005 Pol. Deg. and Stab. $89492-500$

22. Jin HH, Min SH, Song YK, Park HC and Yoon SY 2010 Pol. Deg. and Stab. 95 1856-61

23. Mathieu LM, Bourban PE and Månson JAE 2006 Comp. Sci. and Tech. 66 1606-14

24. Rakovsky A, Gotman I, Rabkin E and Gutmanas EY 2014 J. Mech. Behav. Biomed. Mat. 32 89-98

25. Johnson AJW and Herschler BA 2011 Acta. Biom. 7 16-30

26. Wan Y, Wu C, Xiong G, Zuo G, Jin J, Ren K, ZhuY, WangZ and Luo H 2015 J. Mech. Behav. Biomed. Mat. 47 29-37

27. Ginjupalli K, Shavi GV, Averineni RK, Bhat M, Udupa N and Upadhya NP 2017 Pol. Deg. and Stab. 144 520-35

28. Martínez C, Fernández C, Prado M, Ozols A and Olmedo DG 2017 J. Biomed. Mat. Res. Part A 105A (4) 1034-45

29. Pettarin V, Brun F, Viana JC, Pouzada AS and Frontini PM 2013 Comp. Sci. and Tech. $7428-36$

30. Zhu XK and Joyce JA 2012 Eng. Frac. Mech. 85 1-46

31. Mülle rKH, Motskin M, Philpott AJ, Routh AF, Shanahan CM, Duer MJ and Skepper JN 2014 Biomat. $351074-88$

32. Motskin M, Wright DM, Muller K, Kyle N, Gard TG, Porter AE and Skepper JN 2009 Biomat. 30 3307-17

33. Perez E, Fama L, Pardo SG, Abad MJ and Bernal C, 2012 Comp. Part B 43 2795-2800 
34. Kang Y, Xu X, Yin G, Chen A, Liao L, YaoY, HuangZ and Liao X 2007 Eur. Pol. J. 43 $1768-78$

35. Kang Y, Yao Y, Yin G, HuangZ, Liao X, Xu X and Zhao G 2009 Med. Eng. \& Phys. 31 589-94

36. Frone AN, Berlioz S, Chailan JF and Panaitescu DM 2013Carbo. Pol. 91 377-84

37. Saeidloua S, Huneaulta MA, Li H and Parkc CB 2012 Prog. Pol. Sci. 37/1657-77

38. Liuyun J, ChengdongX, Lixin J and Lijuan X 2013 Thermo. Acta 565 52-7

39. PerssonM, Lorite GS, Cho S-W, Tuukkanen J and Skrifvars M 2013 App. Mat. Interf. 5 $6864-72$

40. Liu X, Wang T, Chow LC, Yang M and Mitchell JW 2014 Int. J. Pol. Sci.ID 827028

41. Zhou WY, Duan B, Wang M and Cheung WL 2009 J. App. Pol. Sci. 113(6) 4100-15

42. Shi X, Zhang G, Siligardi C, Ori G and Lazzeri A 2015 J. Nanomat. ID 905210

43. Wu D, Wu L, Zhang M and Zhao Y 2008 Pol. Deg. Stab. 93 1577-84.

44. Liu Z, Chen Y and Ding W 2016 J. Appl. Pol. Sci. 13343381 1-11

45. Mirzadeh A, Ghasemi H, Mahrous F and Kamal MR 2015 J. Appl. Polym. Sci. 132, $426641-11$

46. Li Y, Han C, Bian J, Han L, Dong L and Gao G 2012 Pol. Comp. 33(10) 1719-27

47. Kiss A, Fekete E and Pukánszky B 2007 Comp. Sci. Tech. 67 1574-83

48. Ahmed J, Auras R, Kijchavengkul T and Varshney SK 2012 J. Food Eng. 111 580-9

49. Perez E, Alvarez V, Perez CJ and Bernal C 2013 Comp. Part B 52 72-83

50. Perez E, Bernal C and Piacquadio M 2012 App. Surf. Sci. 258 8940-45

51. Santana OO, Rodríguez C, Belzunce J, Gámez-Pérez J, Carrasco F and Maspoch MLl 2012 Pol. Test. 29 984-90

52. Százdi L, Pozsgay A and Pukánszky B 2007 Eur. Pol. J. 43 345-59

53. Százdi L, Pukánszky BJr, Vancso GJ and Pukánszky B 2006 Pol. 47 4638-48 
54. Pukánszky B and Maurer FHJ 1995 Pol. 36(8) 1617-25

55. Lauke B 2008 Comp. Sc. Tech. 68 3365-72

56. Williams JG 2012 Comp. Sc. Tech. 70 885-91

57. Karger-Kocsis J, Khumalo VM, Bárány T, Mészáros L and Pegoretti A 2013 Comp. Inter. 20(6) 395-404

58. Thio YS, Argon AS and Cohen RS 2004 Pol. 45 3139-47 
Table 1: Thermal properties of PLA composites.

\begin{tabular}{|c|c|c|c|c|c|}
\hline & $\mathbf{T}_{\mathbf{g}}\left({ }^{\circ} \mathbf{C}\right)$ & $\mathbf{T}_{\text {cc }}\left({ }^{\circ} \mathbf{C}\right)$ & $\mathbf{T}_{\mathbf{m} 1}\left({ }^{\circ} \mathbf{C}\right)$ & $\mathbf{T}_{\mathrm{m} 2}\left({ }^{\circ} \mathbf{C}\right)$ & $\mathbf{X}_{\mathrm{c}}(\%)$ \\
\hline \multicolumn{6}{|c|}{ Intensive mixer } \\
\hline PLA & 62.5 & 117.5 & 150.7 & 157.7 & 6.7 \\
\hline PP-1\% HA & 62.6 & 116.4 & 150.2 & 156.8 & \\
\hline PP-2.5\% HA & 61.7 & 117.3 & 149.1 & 6.2 & \\
\hline PP-1\% $\%$-TCP & 62.5 & 115.6 & 149.9 & & 8.7 \\
\hline PP-2.5\% $\beta$-ТCP & 62.8 & 114.6 & 149.8 & & 4.7 \\
\hline \multicolumn{6}{|c|}{ Twin screw extruder } \\
\hline PLA & 60.5 & 117.4 & 1 & 156.9 & 8.9 \\
\hline PP-1\%HA & 61.5 & 108.5 & 14 & 156.8 & 10.9 \\
\hline PP-2.5\% HA & 61.7 & 108.9 & 77.6 & 156.1 & 8.8 \\
\hline PP-1\% $\%$-TCP & 62.2 & 114.8 & 150.2 & 157.6 & 5.2 \\
\hline PP-2.5\% $\beta$-TCP & 61.8 & 109.5 & 148.2 & 156.3 & 6.8 \\
\hline
\end{tabular}

$T_{g}$ : glass transition temperature, $T_{c c}$ : cold crystallization temperature, $T_{m 1-2}$ : melting temperatures, $X_{c}$ : crystallinity 
Figure 1. Particle size distributions for HA and $\beta$-TCP.

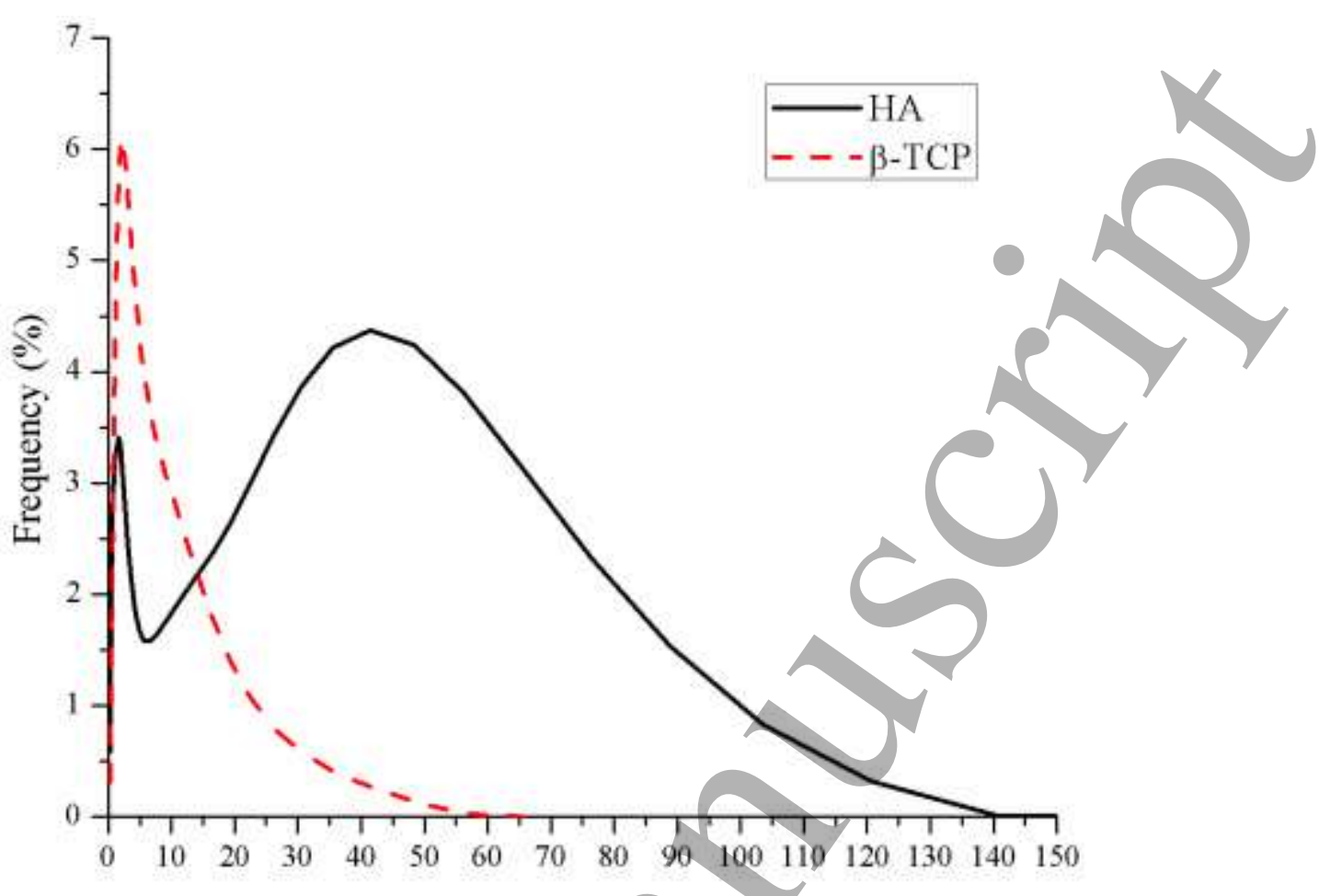

Particle size ( $\mu \mathrm{m})$ 
Figure 2. SEM images of: a.1) PLA-2.5 wt.\% HA, a.2) PLA-2.5 wt.\% $\beta$-TCP obtained with mixer and b.1) PLA-2.5 wt.\% HA, b.2) PLA-2.5 wt.\% $\beta$-TCP obtained with extruder.
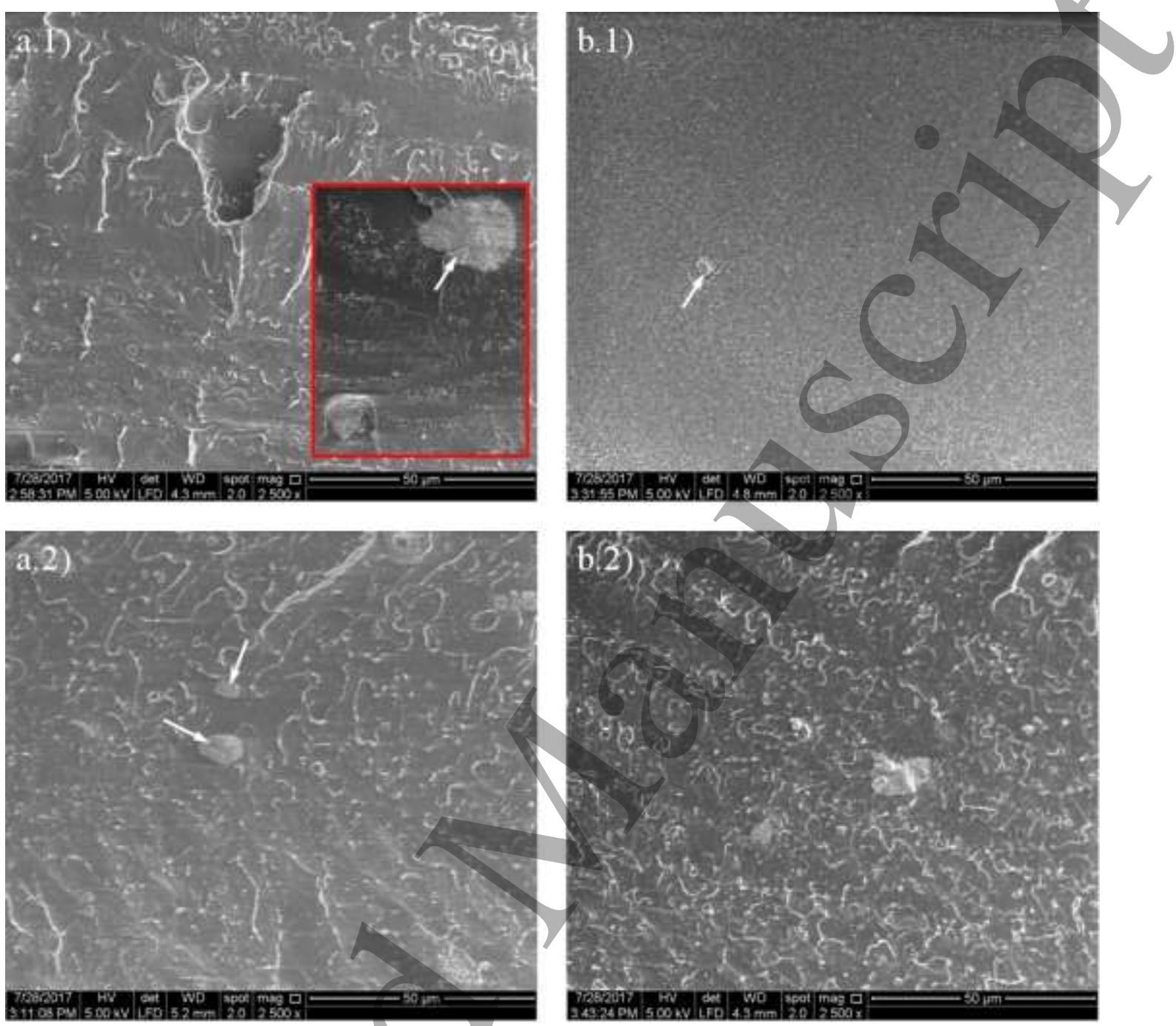
Figure 3. DSC thermograms for PLA composites obtained with extruder: a) PLA-HA and b) PLA- $\beta$-TCP.

a)

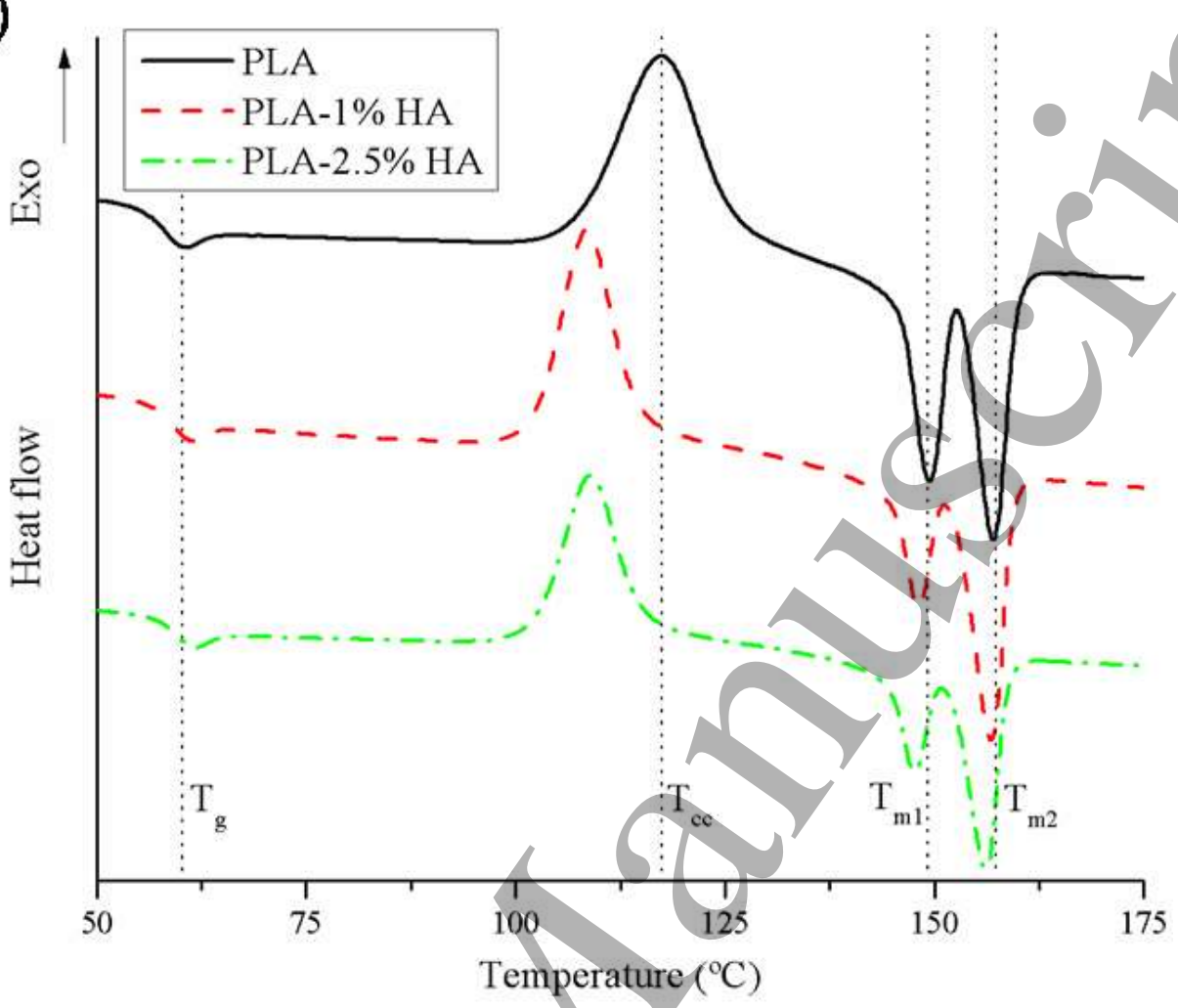

b)

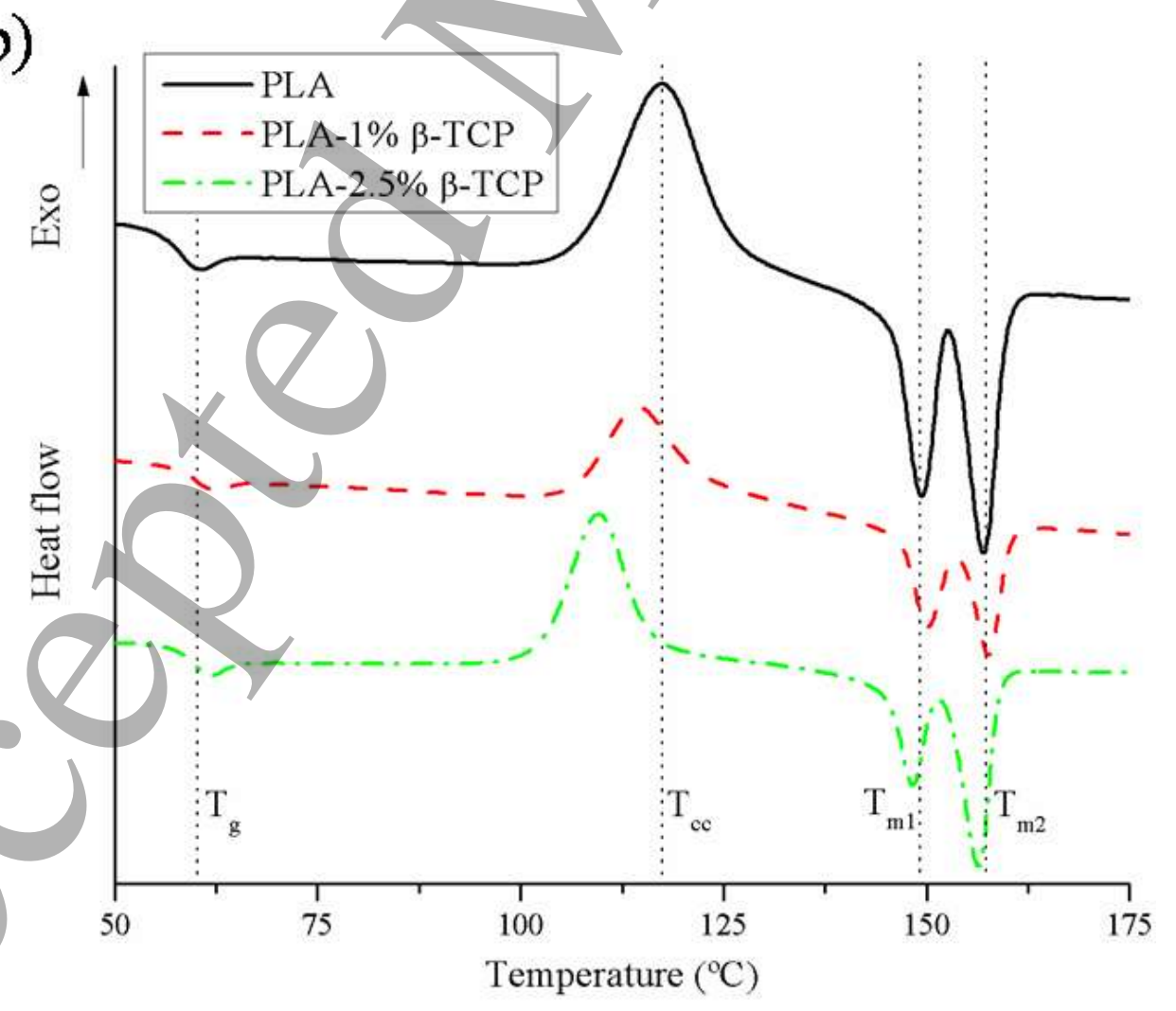


Figure 4. Rheological properties for PLA composites obtained with extruder: a) complex viscosity $\left(n^{*}\right)$, b) storage modulus $\left.\left(\mathrm{G}^{\prime}\right), \mathrm{c}\right)$ Han diagram and d) Cole-Cole diagram.

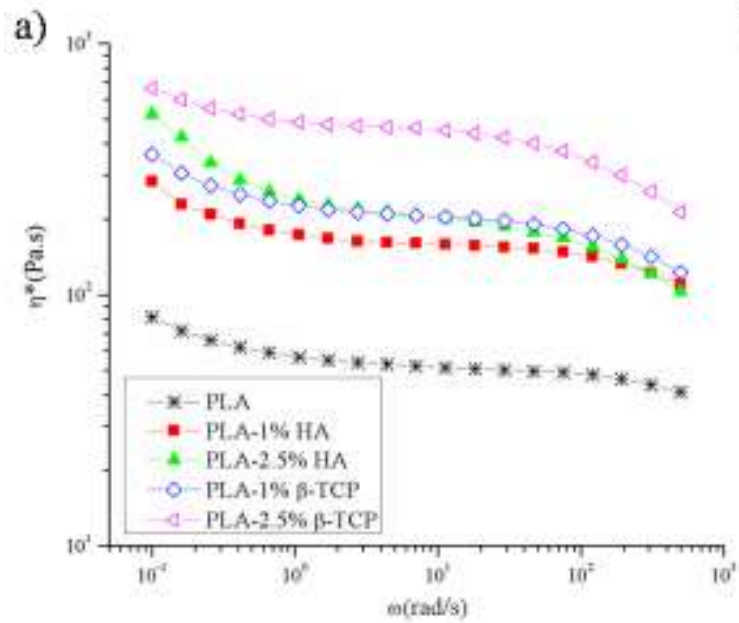

c)

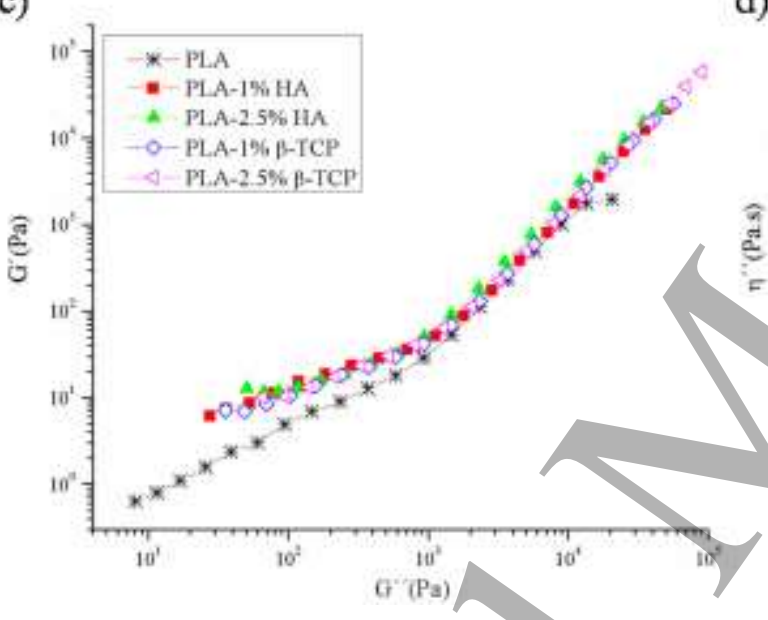

b)

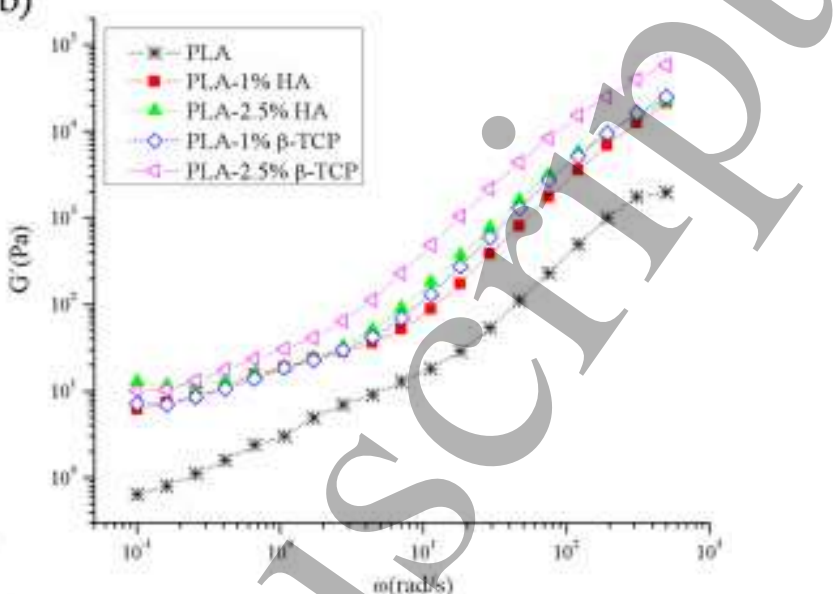

d)

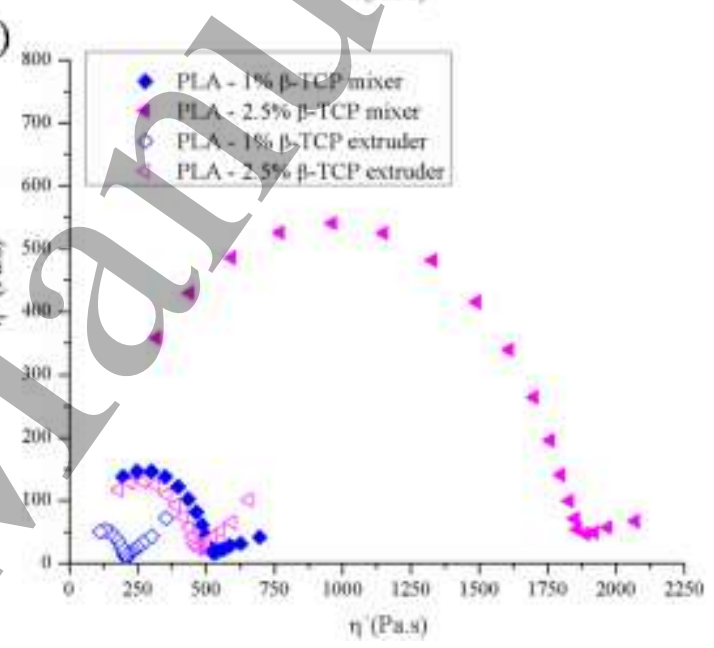


Figure 5. Stress-strain curves for PLA composites obtained with different compounding

methods: a) intensive mixer and b) twin screw extruder.

a. 1)

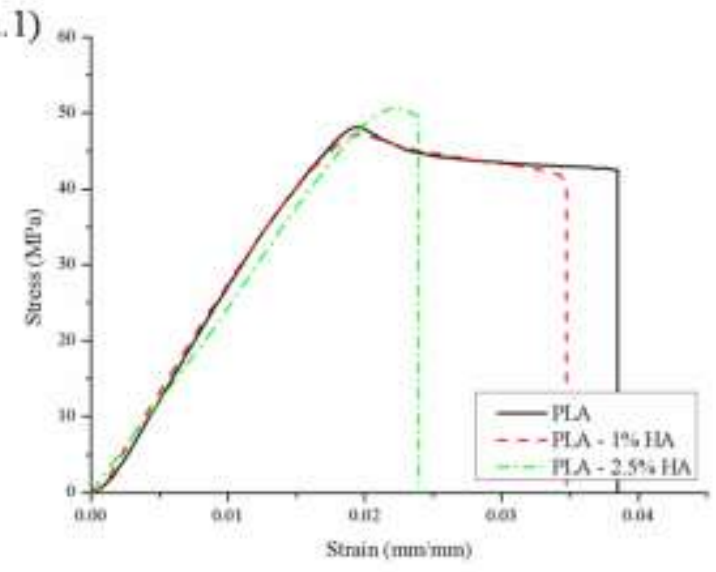

b.1)

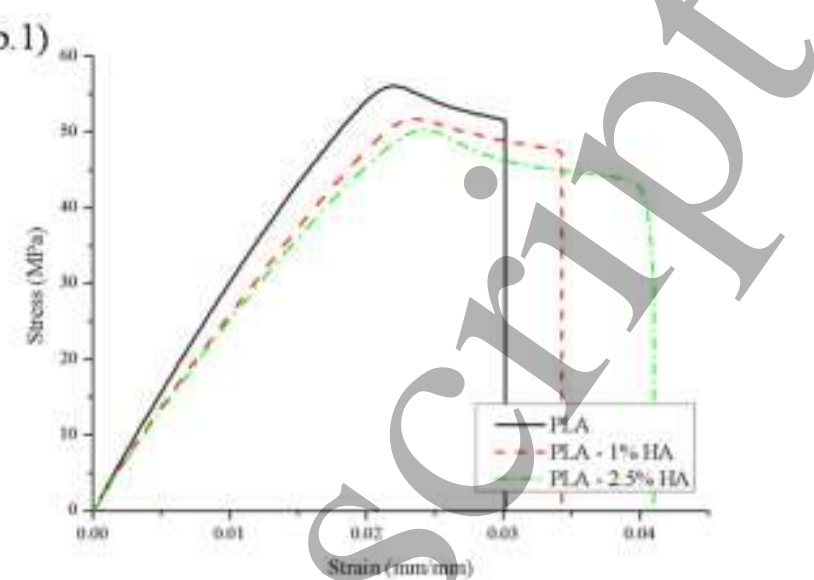

b.2)

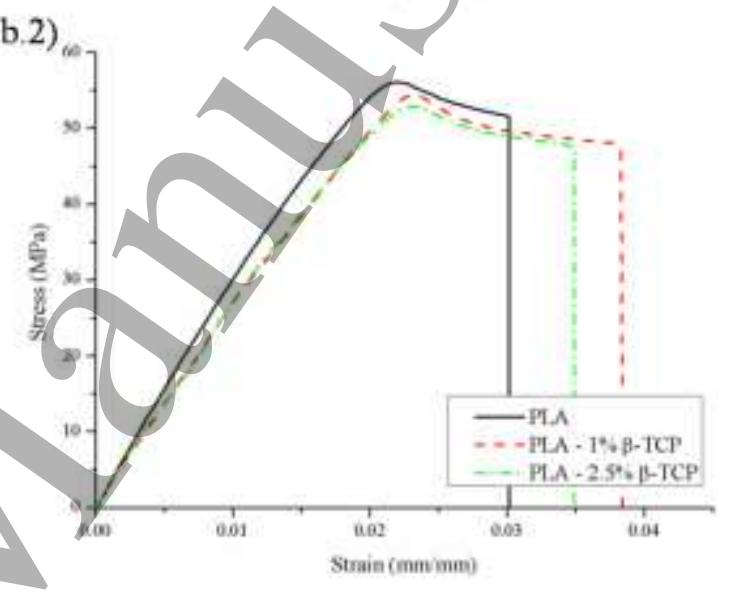

a.2)

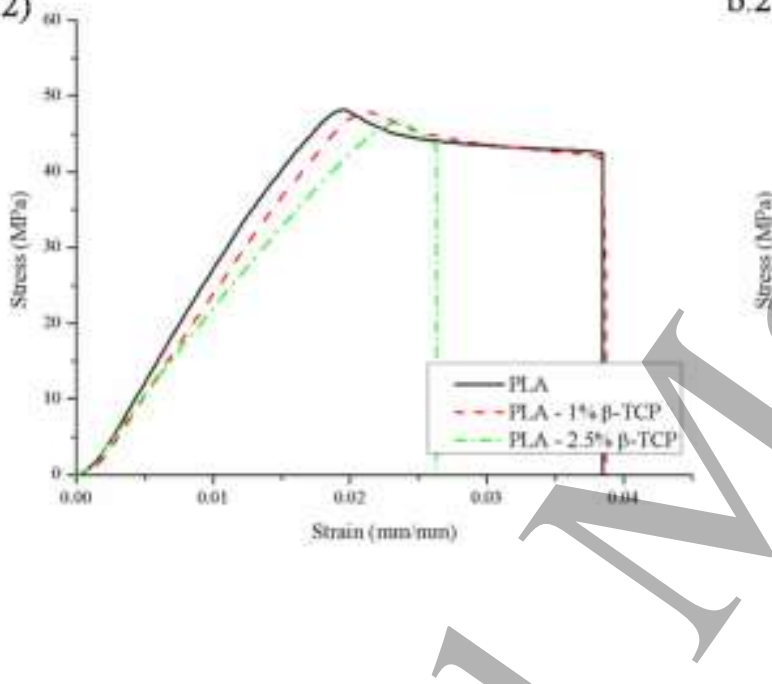

10

12

13

14
15

16 
Figure 6. Tensile parameters for PLA composites obtained with different compounding methods: a) intensive mixer and b) twin screw extruder.

a.1)

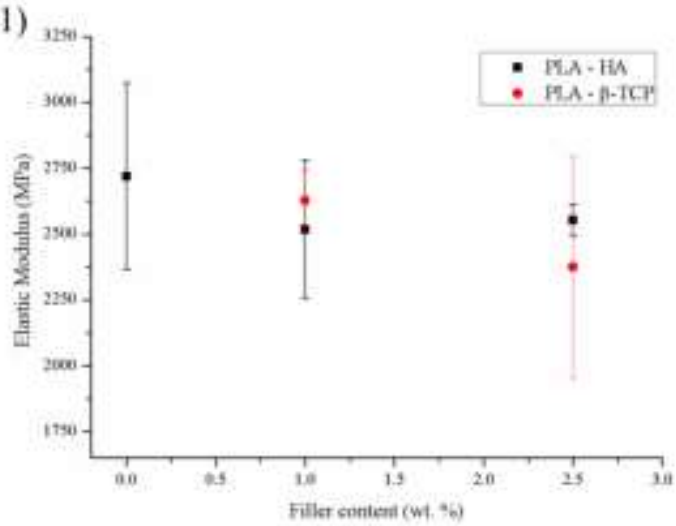

a.2)

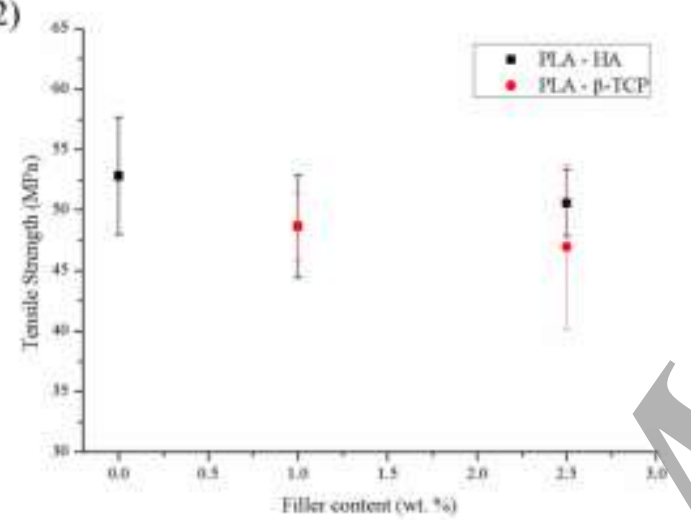

b.1)

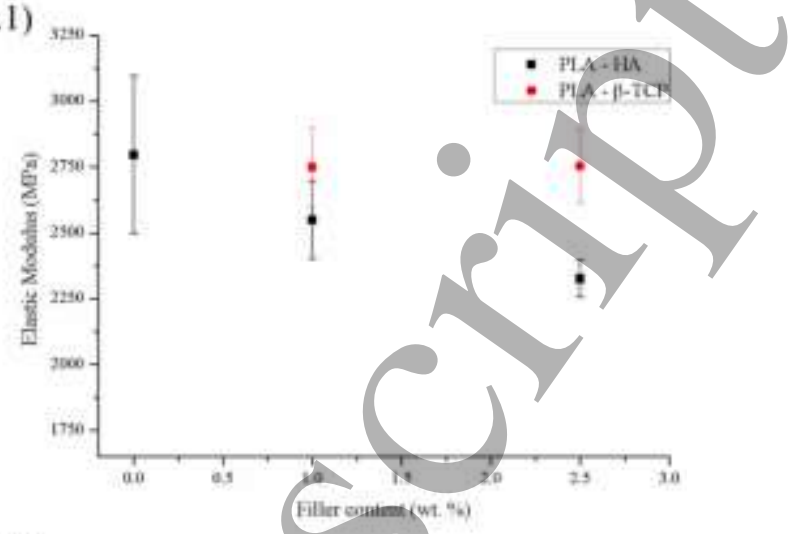

b.2)

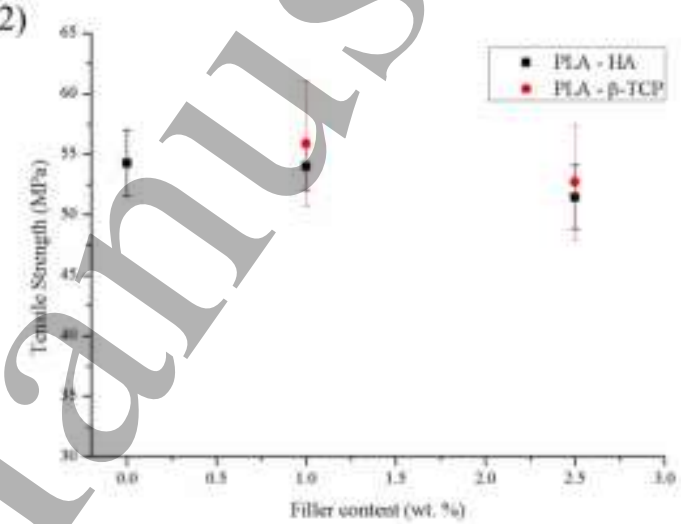

a.3)

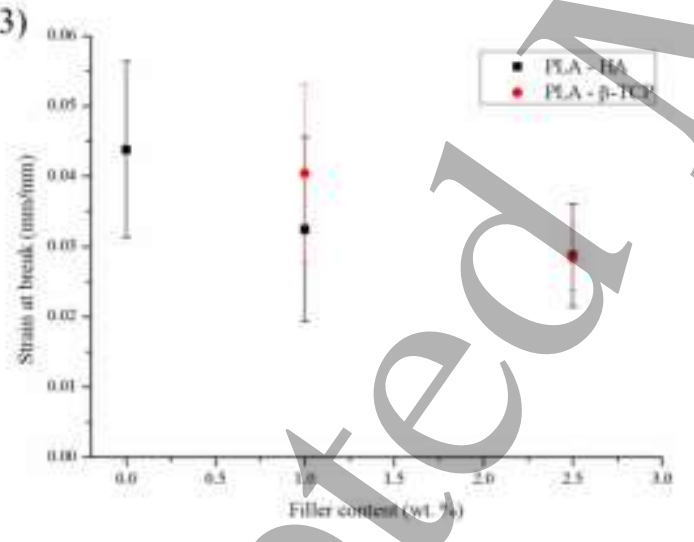

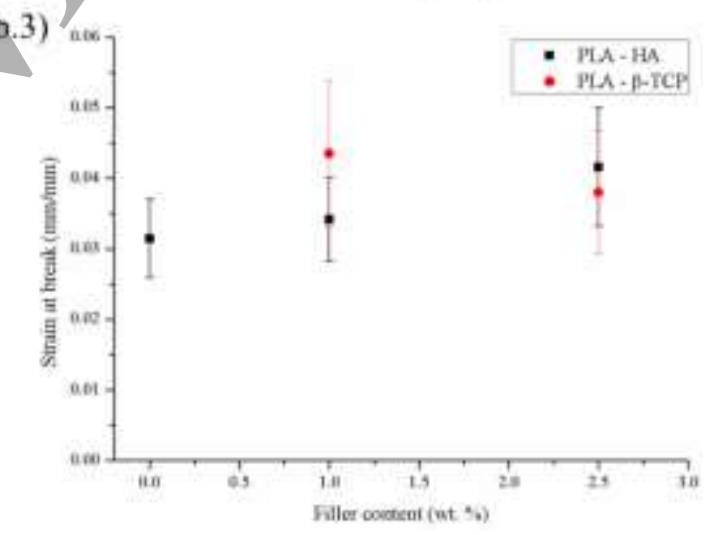


Figure 7. Tensile tested surfaces of: a.1) PLA, a.2) PLA-2.5 wt.\% HA, a.3) PLA-2.5 wt.\% $\beta$-TCP obtained with mixer and b.1) PLA, b.2) PLA-2.5 wt.\% HA, b.3) PLA-2.5 wt.\% $\beta$ TCP obtained with extruder.
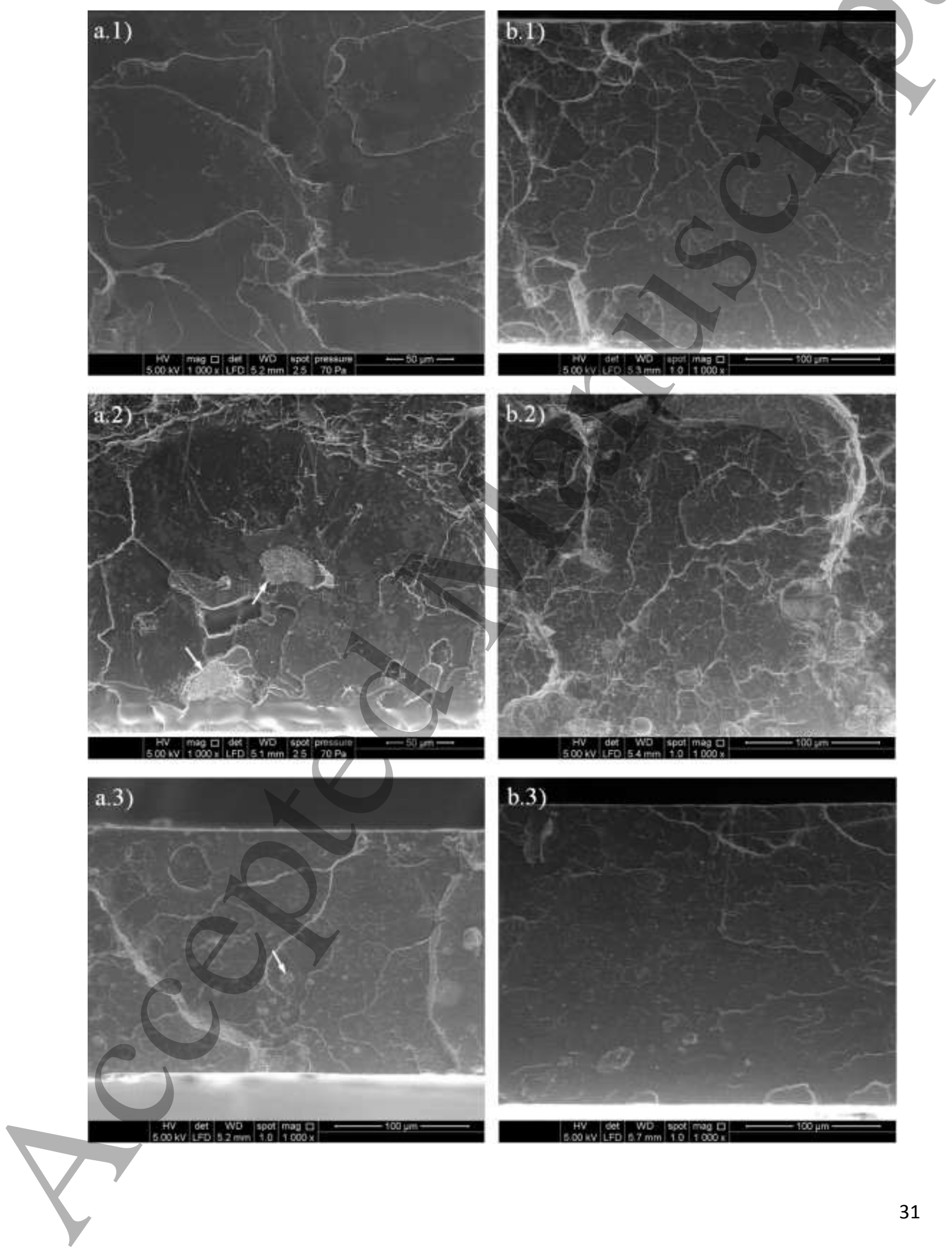
Figure 8. Load-displacement curves for PLA composites obtained with different compounding methods: a) intensive mixer and b) twin screw extruder.

a.1)

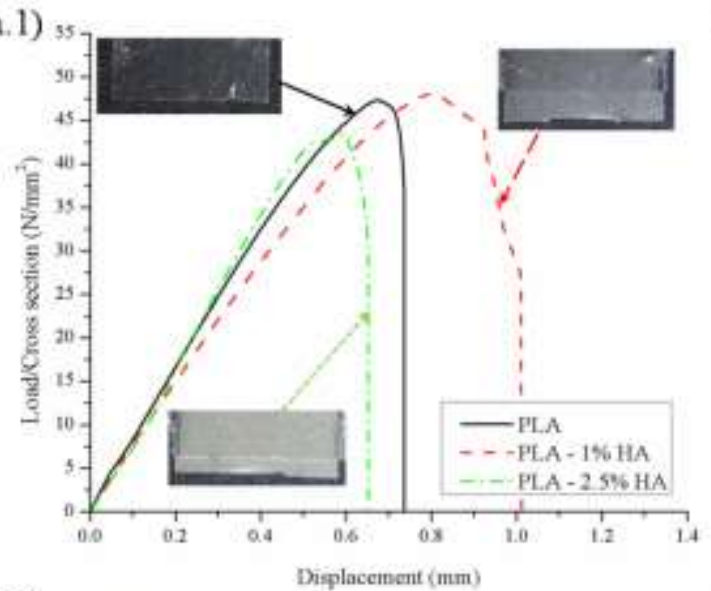

a.2)

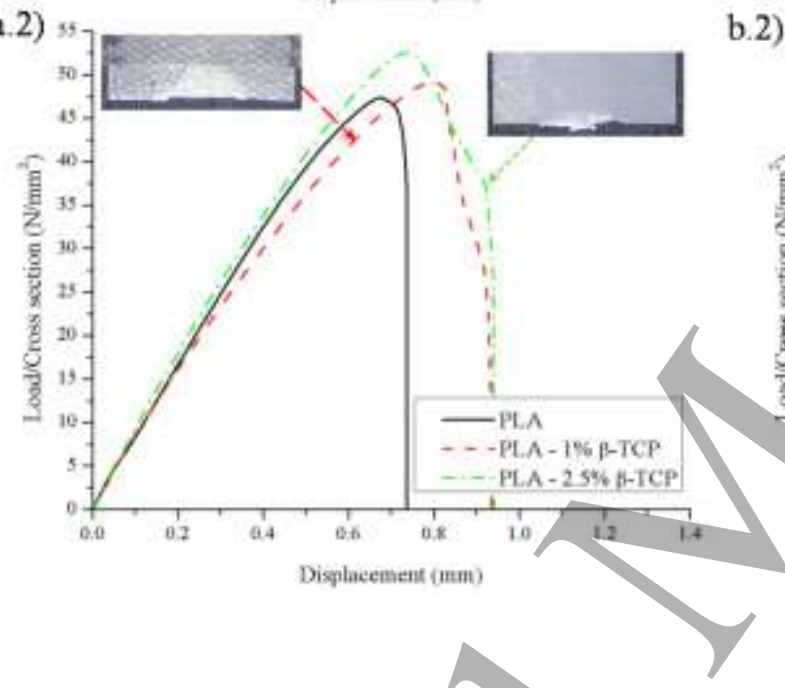

b.1)
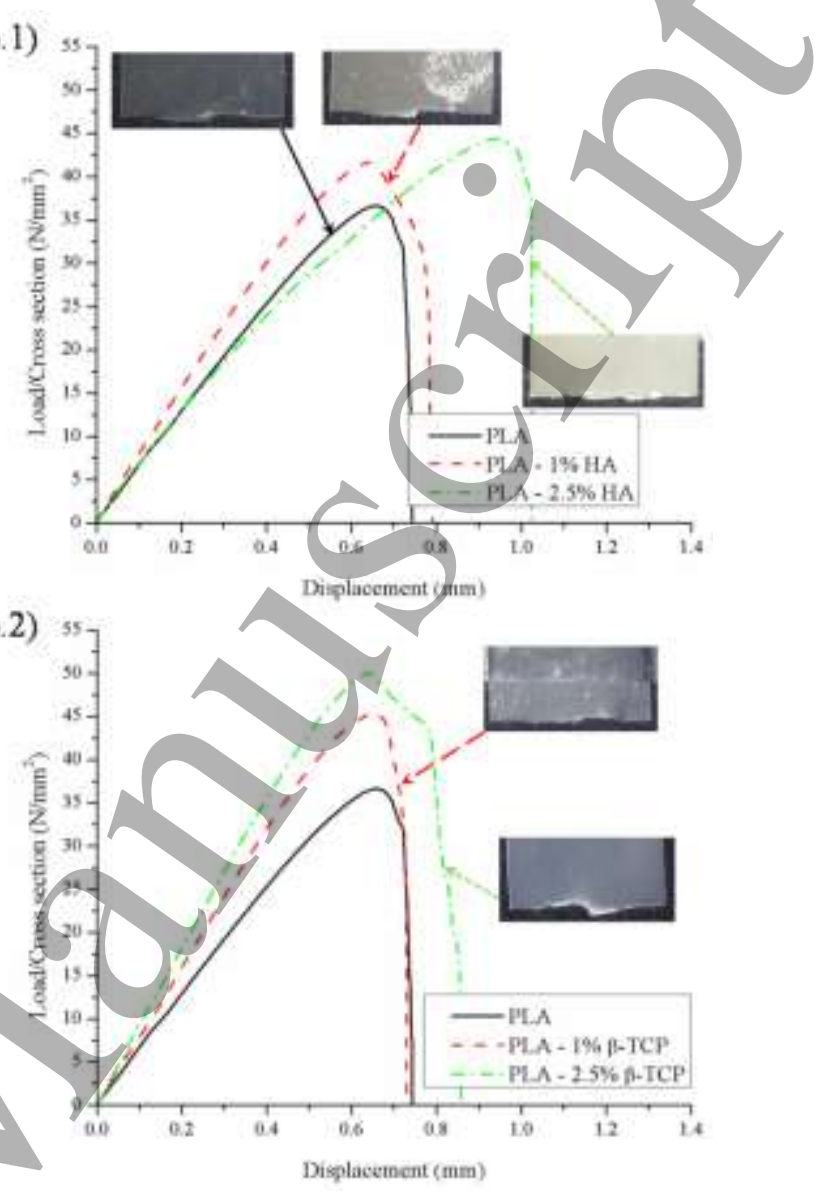

37 
Figure 9. Fracture toughness characterization for PLA composites: a) stress intensity factor (a.1: mixer, a.2: extruder) and b) propagation fracture toughness (b.1: mixer, b.2: extruder).

a. 1)

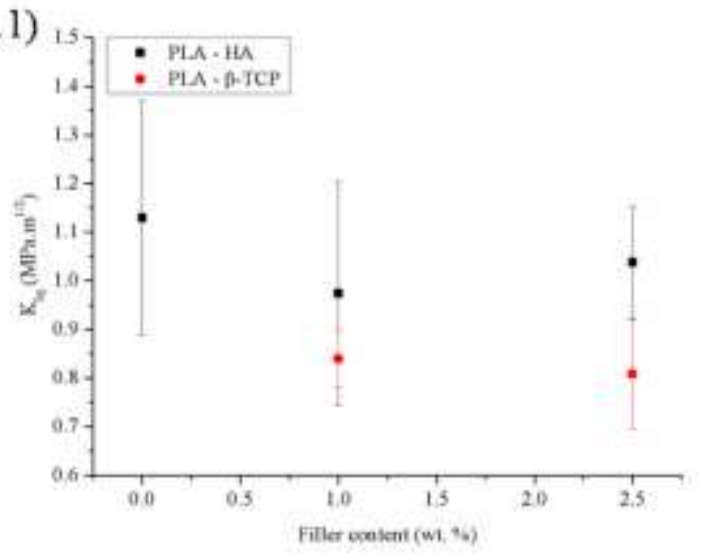

b.1)

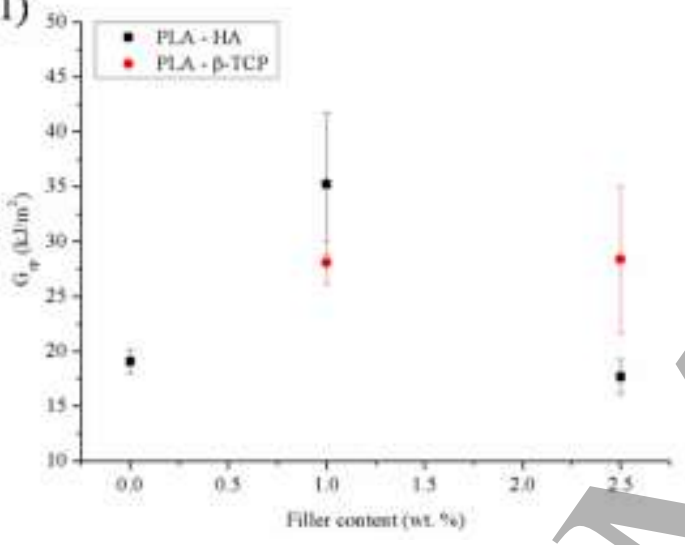

a.2)

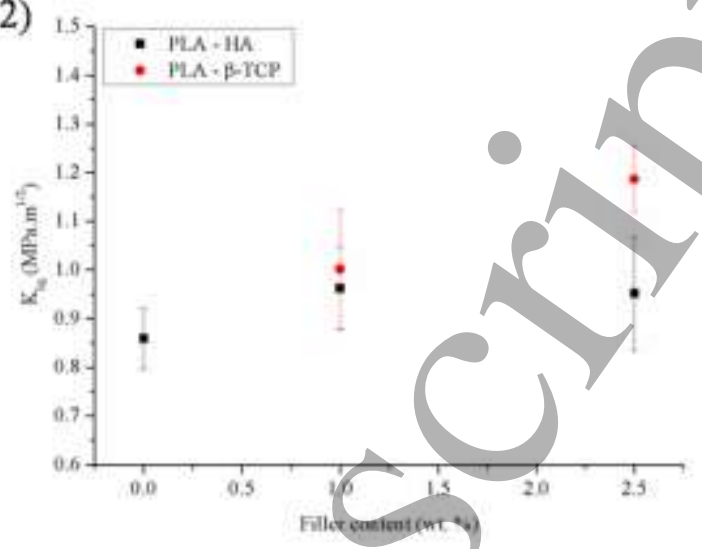

b.2)

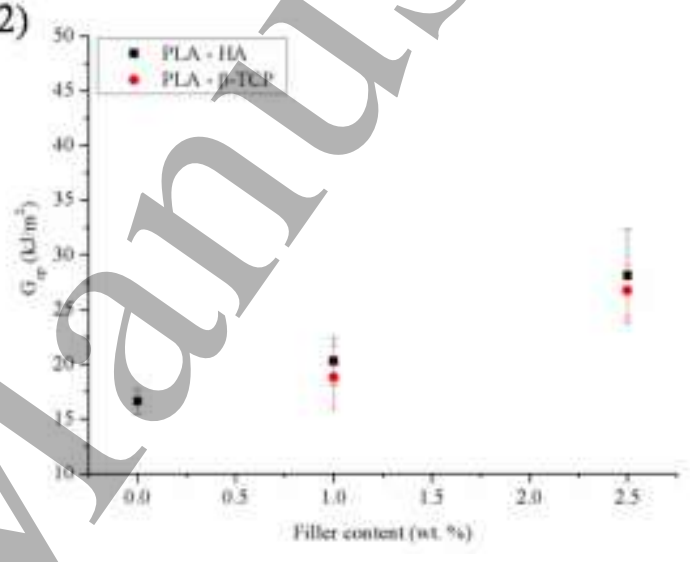


Figure 10. Reduced strain energy release rate $\left(G_{\text {crel }}\right)$ for composites obtained with different compounding methods: a) PLA-HA and b) PLA- $\beta$-TCP.

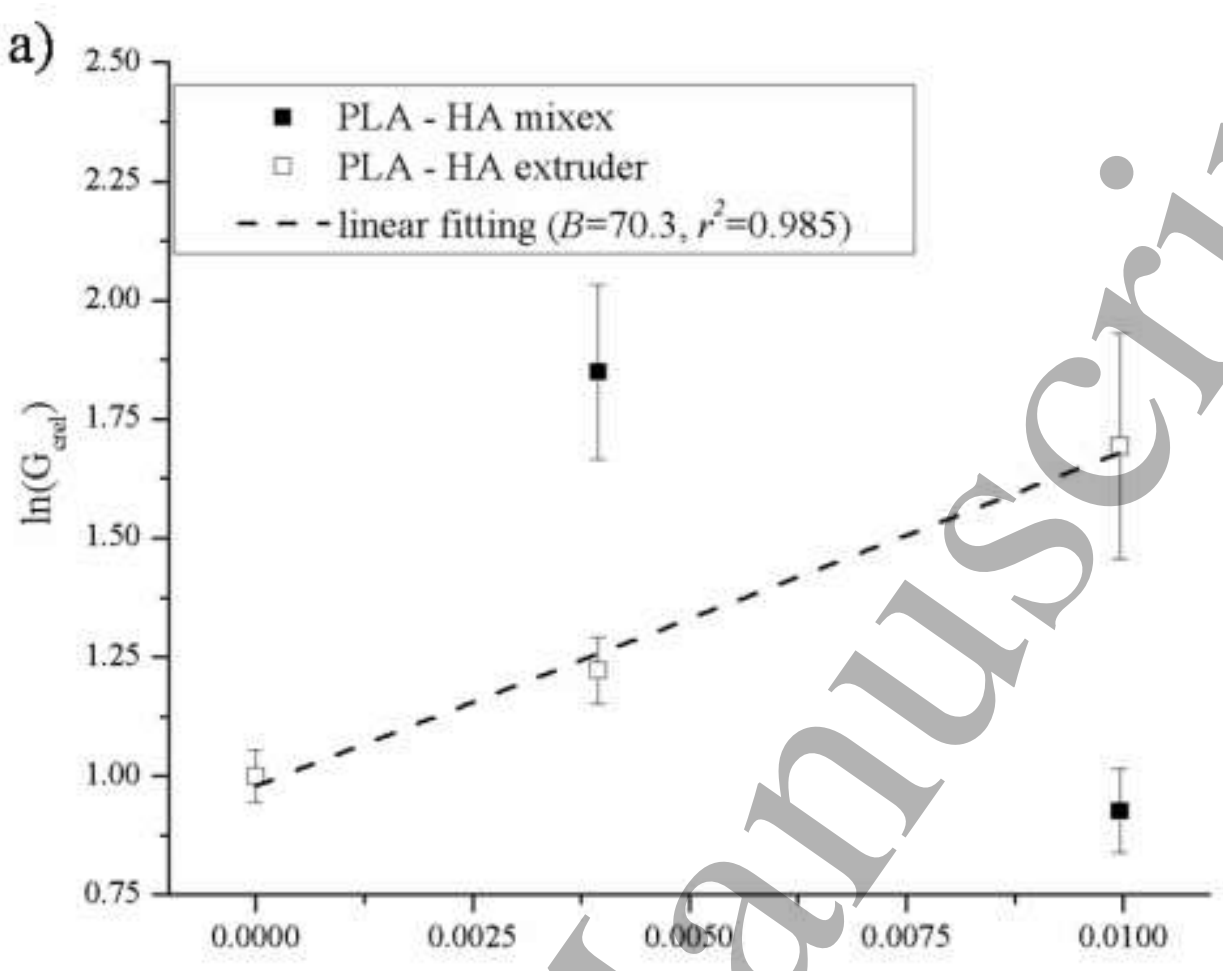

Filler volume fraction

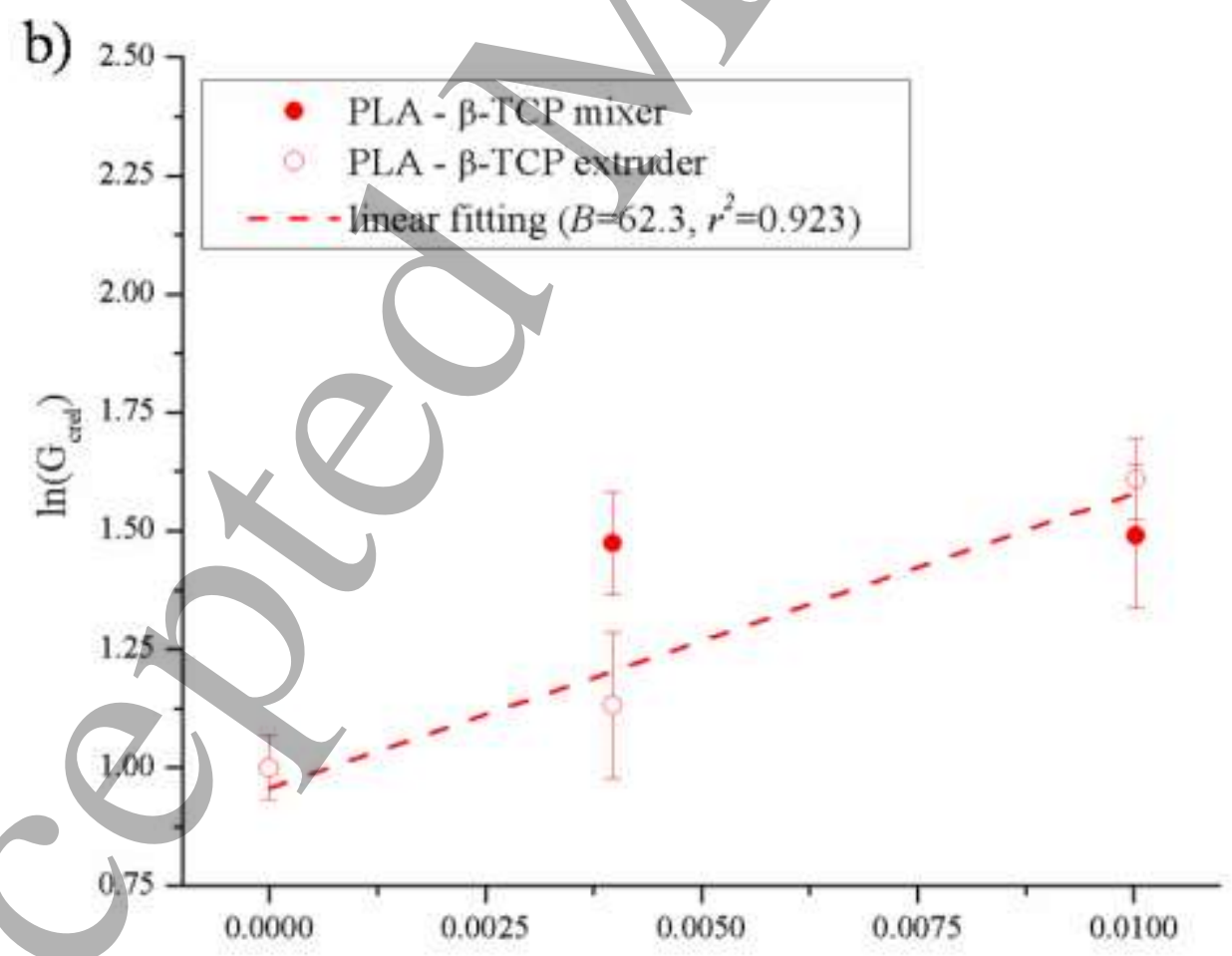

Filler volume fraction 
Figure 11. Quasi-static fractured surfaces of: a.1) PLA, a.2) PLA-2.5wt.\% HA, a.3) PLA2.5wt.\% $\beta$-TCP obtained with mixer and b.1) PLA, b.2) PLA-2.5wt.\% HA, b.3) PLA$2.5 \mathrm{wt} . \% \beta$-TCP obtained with extruder.
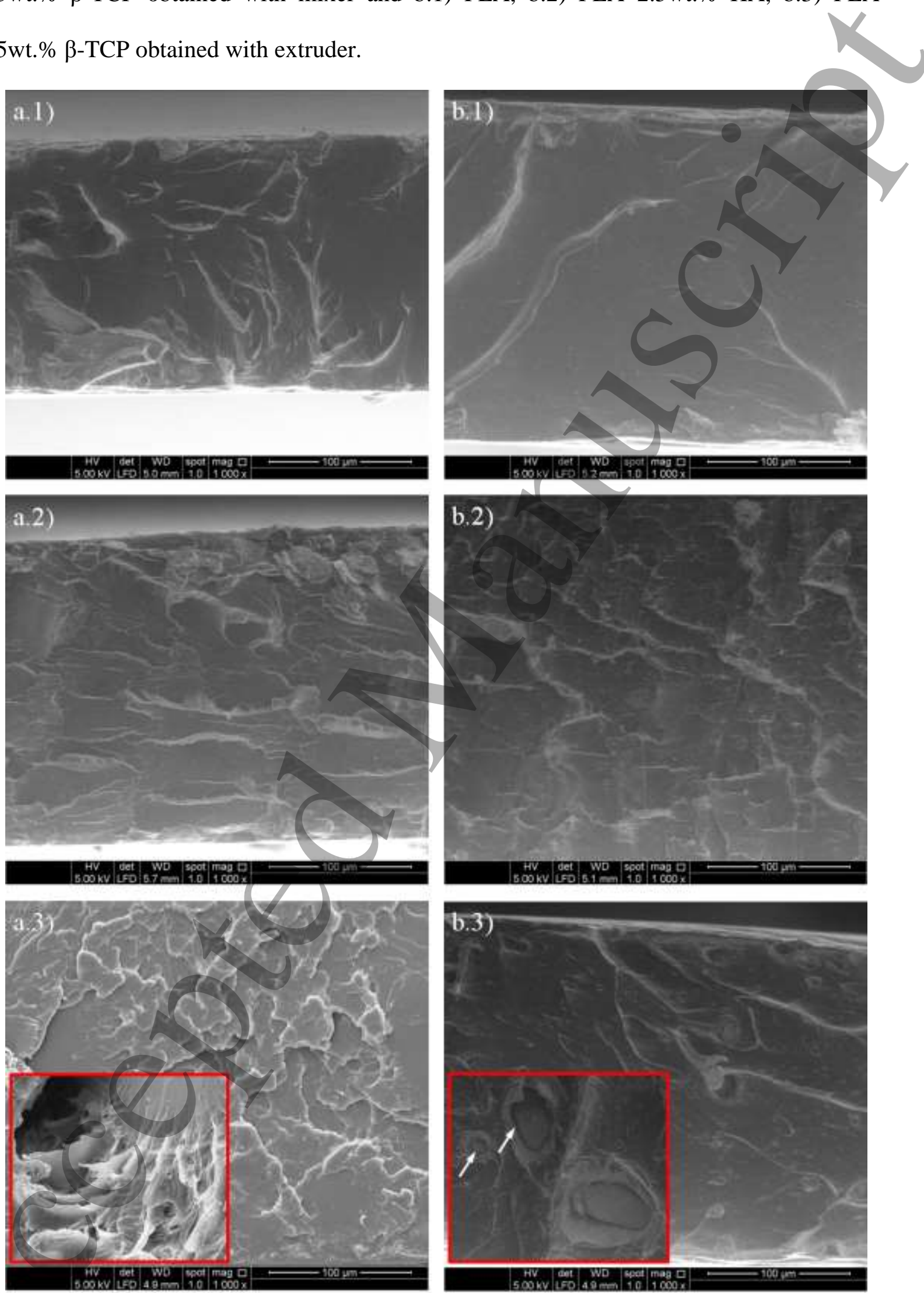